\title{
Increasing access to magnesium sulphate in Nigeria
}

Population Council

Follow this and additional works at: https://knowledgecommons.popcouncil.org/departments_sbsr-rh

Part of the Demography, Population, and Ecology Commons, Family, Life Course, and Society Commons, International Public Health Commons, and the Maternal and Child Health Commons How does access to this work benefit you? Let us know!

\section{Recommended Citation}

"Increasing access to magnesium sulphate in Nigeria," Ending Eclampsia Policy Brief. Washington, DC: Population Council, 2016. 
Maternal and newborn deaths due to pre-eclampsia and eclampsia (PE/E) are preventable, yet in Nigeria, this is the most significant direct cause of maternal deaths.

\section{THE PROBLEM}

Despite global efforts to reduce preventable maternal and neonatal mortality, Nigeria's maternal mortality ratio is estimated at 576 deaths per 100,000 live births and neonatal death is estimated at 37 per 1,000 live births.

In Nigeria, hypertensive disorders in pregnancy (including $\mathrm{PE} / \mathrm{E}$ ) is the most common cause of maternal mortality, contributing to $29 \%$ of maternal deaths. As a major killer of pregnant women, greater uptake of effective, low-cost interventions to prevent, detect, and treat $\mathrm{PE} / \mathrm{E}$ is needed at primary health care facilities.

The World Health Organization (WHO) recommends magnesium sulphate $\left(\mathrm{MgSO}_{4}\right)$ as the most effective, safe, and low-cost drug for treating pre-eclampsia and eclampsia.

To increase access and use of $\mathrm{MgSO}_{4}$ in Kano State, the Population Council trained lower-cadre health care providers in antenatal clinics to detect pre-eclampsia early and instituted timely and appropriate management by administering the loading dose of $\mathrm{MgSO}_{4}$ and referring for follow up care. This intervention, supported by the John D. and Catherine T. MacArthur Foundation, reduced the maternal mortality rate due to $\mathrm{PE} / \mathrm{E}$ by $40 \%$ in project sites.

\section{APPROACH}

In preparation for the study, the Council engaged with stakeholders and advocated for the adoption of protocols allowing primarily health care providers to administer the intramuscular (IM) loading dose of $\mathrm{MgSO}_{4}$ to women with severe pre-eclampsia and eclampsia prior to referral to a higher level facility. To gain acceptance of the proposed intervention, the Council worked closely with representatives from the Federal Ministry of Health and with community gatekeepers, such as traditional leaders and social workers.

\section{PE/E IN BRIEF}

- Pre-eclampsia is a condition in pregnant women marked by an increase in blood pressure and protein in urine after 20 weeks gestation.

- Providing high quality antenatal care improves the prevention and early detection of pre-eclampsia and can prevent its progression to eclampsia.

- Eclampsia is a life-threatening condition characterized by convulsions in women with PE.

- Women in developing countries are 300 times more likely to die from eclampsia than women in developed countries.

- Pre-eclampsia and eclampsia can be managed by administering antihypertensive drugs and magnesium sulphate $\left(\mathrm{MgSO}_{4}\right)$.

- $\mathrm{MgSO}_{4}$ is the safest and most effective treatment for severe preeclampsia and eclampsia, and is one of the 13 UN Life-Saving Commodities for Women and Children.

- PE/E and other hypertensive disorders in pregnancy increase the risk of pre-term births, which can lead to low birth weight, anemia, and stunting.

- Improved prevention, increased detection, and effective treatment of $\mathrm{PE} / \mathrm{E}$ can prevent unnecessary maternal and newborn deaths.

\section{MacArthur Foundation}

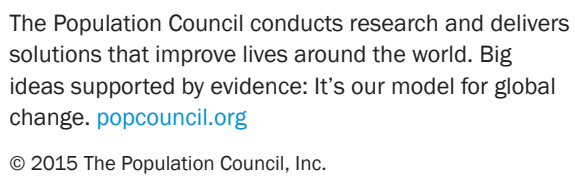

The Population Council conducts research and delivers solutions that improve lives around the world. Big ideas supported by evidence: It's our model for global change. popcouncil.org

(c) 2015 The Population Council, Inc.

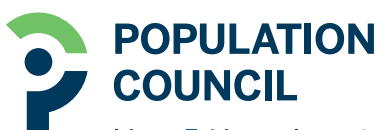

Ideas. Evidence. Impact. 
Between 2008 and 2014, the intervention occurred in two phases. The first phase (2008-2011) involved selecting 10 secondary health facilities in Kano State. Once selected, the Council then trained, mentored, and supervised 40 providers from these facilities to detect and manage PE/E patients. This included training them to administer a loading dose of $\mathrm{MgSO}_{4}$. Continued mentorship consisted of monthly visits from trainers, and every patient with pre-eclampsia or eclampsia was monitored for up to six weeks after delivery.

The providers then trained and mentored additional providers at their respective health facilities on the use of $\mathrm{MgSO}_{4}$, which the Council supplied to the facilities. Once the provided stock of $\mathrm{MgSO}_{4}$ ran out, the state Ministry of Health took over procurement.

The second phase of the intervention (2012-2014) focused on primary health care facilities, and divided them into two groups - an experimental and a control. In the experimental group, researchers trained providers to administer a loading dose of $\mathrm{MgSO}_{4}$. In the control group, researchers did not train providers to use $\mathrm{MgSO}_{4}$.

\section{RESULTS}

Results showed that lower-cadre health providers can reduce maternal mortality related to $\mathrm{PE} / \mathrm{E}$ if trained to administer $\mathrm{MgSO}_{4}$. Prior to the study, the Council found maternal mortality caused by PE/E was at $15 \%$ in Kano. In the experimental group, it decreased to $1.7 \%$. In the control group, maternal deaths remained the same.

\section{SCALE UP}

The Council intends to replicate this intervention in other states in Nigeria to reduce maternal deaths related to $\mathrm{PE} / \mathrm{E}$. Moving forward, the Council will modify this intervention by also training providers at primary health care facilities to manage hypertension by using antihypertensive drugs and will include a community component to increase awareness of signs and symptoms and information that details where and when to seek treatment.

\section{RESOURCES}

Okereke, E., Ahonsi, B., Tukur, J., Ishaku, S. M., \& Oginni, A. B. (2012). Benefits of using magnesium sulphate $\left(\mathrm{MgSO}_{4}\right)$ for eclampsia management and maternal mortality reduction: lessons from Kano State in Northern Nigeria BMC Research Notes, 5, 421.

Tukur, J., Ahonsi, B., Ishaku, S. M., Araoyinbo, I., Okereke, E., \& Babatunde, A. O. (2013). Maternal and fetal outcomes after introduction of magnesium sulphate for treatment of preeclampsia and eclampsia in selected secondary facilities: a low-cost intervention. Maternal and Child Health Journal, 17(7), 1191-1198.

\section{FIGURE 1 Kano Model for increaseing access to $\mathrm{MgSO}_{4}$}

Phase I: Advocacy \& Training

Implementing partners conduct

initial training and ongoing

monitoring/supervision

Phase II: Task-shifting to PHC

Implementing partners conduct

initial training and ongoing

monitoring/supervision

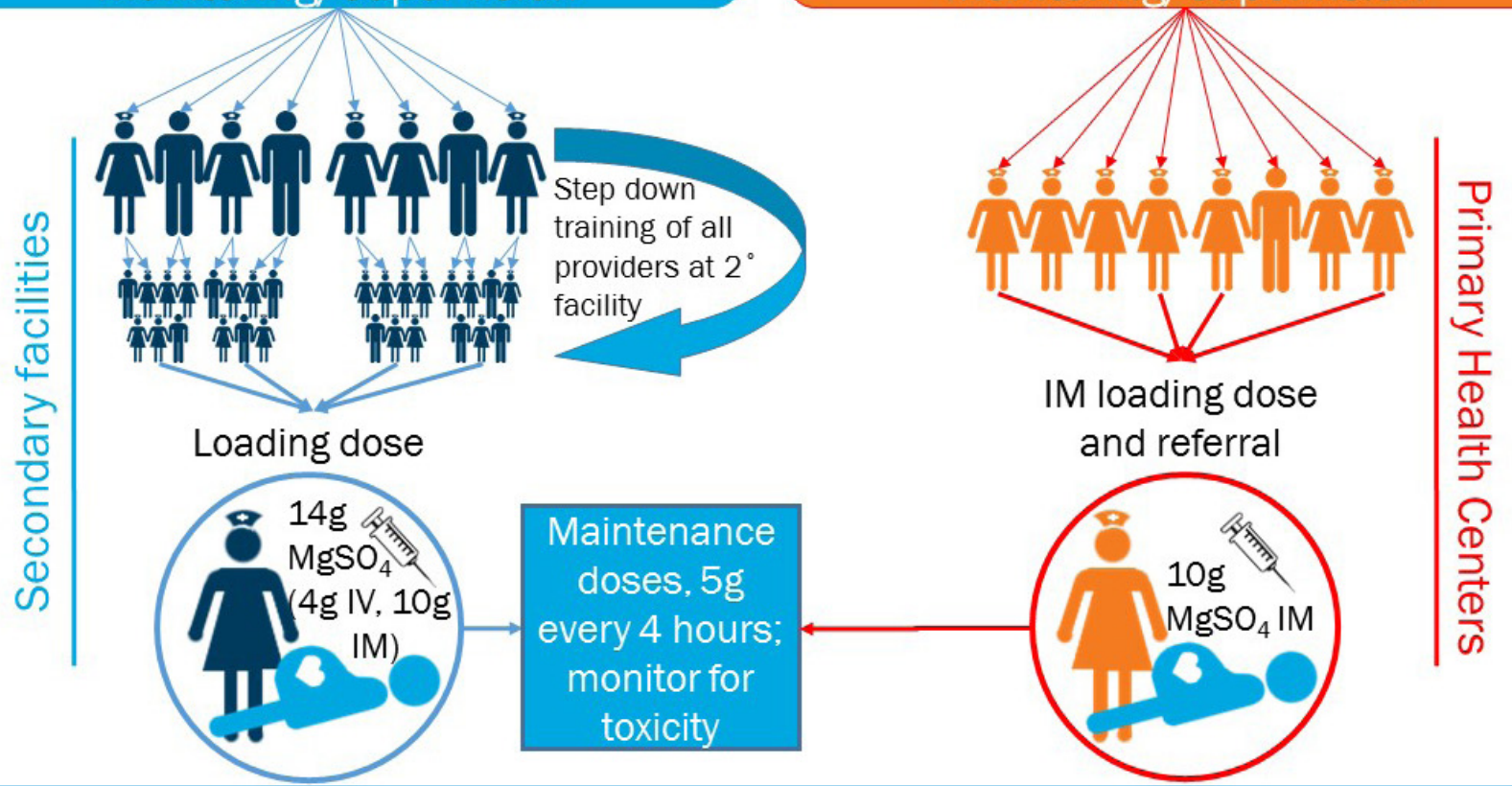

Suggested Citation: Increasing Access to Magnesium Sulphate in Nigeria Brief. Population Council. 2016. 